\title{
SOBRE O DECORUM: DOS CLÁSSICOS À PÓS-MODERNIDADE
}

\author{
Eliana Amarante de Mendonça \\ Mendes ${ }^{1}$
}

Quod honestum, quod rectum, quod decorum apellamus, quod idem interdum virtutis nomine ampectimur.

(Cícero, Tusc. II, 13,20) ${ }^{2}$

\section{Resumo}

Considerando a importância do decorum para assegurar o bom relacionamento humano, especialmente na esfera pública, e que episódios de quebra de decorum são recorrentes na vida pública brasileira, propomo-nos a resgatar esse conceito clássico, uma vez que sua revalorização é oportuna e urgente. Apresentamos, então, uma revisão bibliográfica histórica desse conceito a partir dos clássicos e verificamos que, embora ele tenha sofrido mutações, seu aspecto fundamental, a íntima ligação com a ética, se mantém até hoje. Evidência disso é existirem, em muitos países, "códigos de ética e decorum" dos órgãos legislativos, judiciais e outros. Verificamos, porém, ser esse conceito sensível à cultura, o que se evidencia na análise constrastiva de uma amostra de episódios de violação ao decorum protagonizados por juízes da Suprema Corte americana e do Supremo Tribunal brasileiro. Constatamos que, embora as violações dos americanos sejam menos graves que as brasileiras, as reações da mídia e dos cidadãos americanos são muito mais enérgicas, pois o decorum para os americanos é um valor de que não abrem mão, enquanto no Brasil é "letra morta", carecendo ser ressuscitada. Refletimos também sobre a arrogância dos poderosos, atitude à qual atribuímos a causa de muitas das ocorrências de quebra de decorum na atualidade.

Palavras-chave: decorum; revisão histórica; análise contrastiva; Brasil; Estados Unidos da América

\section{INTRODUÇÃO}

O século XX foi uma época caracterizada por grandes mudanças filosóficas: pela renúncia a alguns ideais científicos, pelo desgaste dos formalismos e dos positivismos. A partir da importância que passou a ser conferida à filosofia da linguagem e à filosofia dos valores, o linguistic turn, começou a tomar corpo uma corrente filosófica e acadêmica

\footnotetext{
${ }^{1}$ Doutora em Filologia e Língua Portuguesa - USP. Professora Titular de Estudos Linguísticos (Programa de Pós-Graduação em Estudos Linguisticos - Faculdade de Letras/UFMG). E-mail: mendes@ufmg.br

2 Quanto mais apelamos pelo honesto, pelo reto, pelo decorum, da mesma forma tanto mais também abraçamo-nos ao nome da virtude. (tradução nossa)
} vol.09, n. 03, Rio de Janeiro, 2016. pp. 
importante, que objetivava recuperar o status da Retórica, conhecimento ancestral intimamente ligado à história da humanidade.

Vários estudiosos começaram, então, a considerar a Retórica novamente como um objeto digno de estudo. Sobretudo os estudos da argumentação, da persuasão, passaram novamente a ocupar lugar de destaque, recebendo hoje uma abordagem interdisciplinar da qual participam filósofos, linguistas, juristas, semioticistas e estudiosos da comunicação. Verifica-se hoje, principalmente, um retorno à ênfase na persuasão, um retorno às modalidades de argumentação identificadas por Aristóteles: a Lógica, tratada em Primeiros Analíticos e Segundos Analíticos; a Dialética, em Tópicos e Refutações Sofísticas; a Retórica, em sua obra homônima.

A contribuição de Perelman, promovendo no âmbito do Direito a revitalização dos ideais clássicos e a consequente desestabilização do positivismo, foi fundamental para o resgate da Retórica.

No entanto, a contribuição dessa antiga arte para os tempos atuais ainda está aquém de sua potencialidade. Há ainda vários aspectos da Retórica, que podem ser de utilidade hoje, ainda esquecidos ou desprezados. Por exemplo, no cenário brasileiro contemporâneo, em que a moderação em si parece ser condenada e em que a transgressão excessiva e a ruptura dos limites parece ser comemorada, cremos ser oportuna uma reflexão sobre o conceito retórico de decorum. Embora esse conceito ainda prevaleça nos códigos de ética nos âmbitos do judiciário e do legislativo, bem como nos de outras categorias, a recorrência nessas esferas de episódios indecorosos com que nos deparamos a todo momento é, no nosso entender, um índice de que sua revitalização é não só oportuna, mas urgente.

\section{DECORUM: REVISÃO HISTÓRICA}

Propomo-nos, pois, a resgatar o conceito de decorum na sabedoria dos clássicos e acompanhá-lo através dos tempos até a contemporaneidade.

\section{A gênese do conceito de decorum}

O conceito de decorum, termo cunhado pelos romanos, tem sua origem em dois conceitos aristotélicos: o primeiro é to prepon, ${ }^{3}$ que costuma ser traduzido como adequação ou propriedade e cuja fonte é o capítulo 7 do livro III de Retórica.

Segundo Aristóteles, 
A linguagem (lexis) será pois apropriada, se apresenta to prepon, isto é, quando expressa o sentido pretendido, está de acordo com a emoção apropriada e é pronunciada de maneira proporcional à seriedade do assunto. Correspondência ao assunto significa que também não devemos falar casualmente sobre assuntos pesados, nem solenemente sobre os triviais; [...] Para expressar emoções, você vai empregar a linguagem raivosa ao falar da indignação; a linguagem de repulsa e discreta relutância para proferir uma palavra quando se fala de impiedade ou maldade; a linguagem de exultação para uma história de glória e de humilhação, para um conto de piedade, e assim por diante em todos os outros casos.4[...]. (ARISTÓTELES, Retórica, 3.7.1, tradução nossa.)

To prepon (propriedade, adequação) depende, pois, da relação entre a léxis (expressão linguística) e o logos (o conteúdo). Ainda segundo Aristóteles, o uso apropriado da léxis "faz a matéria mais credível", levando o orador a parecer credível mesmo se não o for." (ARISTOTELES, Retórica, 3,7.4,tradução nossa)

Para esse filósofo, "[...] o uso oportuno ou inoportuno da léxis é um fator comum a todos os gêneros de Retórica, 5 ou seja, aos gêneros judicial, deliberativo e epidítico. (ARISTÓTELES, Retórica, 3.7.8, tradução nossa)

Explica, ainda:

Essa adequação da linguagem é uma coisa que faz com que as pessoas acreditem na verdade da sua história: suas mentes concluem falsamente que você é de confiança com base no fato de que os outros se comportam como você comporta, quando as coisas são como você as descreve e, portanto, leva a que sua história seja tida como verdade, sendo assim ou não. (ARISTÓTELES , Retórica, 3,7,4, tradução nossa) ${ }^{6}$

A segunda contribuição grega para a teoria de decorum é o conceito de kairós. Atribui-se a gênese desse conceito a uma teoria de Pitágoras relativa ao equilíbrio universal apropriado $^{7}$; na Retórica costuma ser definido como — sincronismo e medida adequada diretamente relacionado com a importância da ocasião, do lugar, do orador e do público, e, também, com a faculdade de usar os meios apropriados em um determinado contexto para chegar à persuasão. Como se vê, os conceitos de kairós, decorum e auditorium são

\footnotetext{
${ }^{3}$ To prepon é também designado pelos pelos gregos to oikeíon e prosêkon, e pelos latinos por accommodatum, decens, proprium e aptum.

4 "Your language will be appropriate if it expresses emotion and character, and if it corresponds to its subject. 'Correspondence to subject' means that we must neither speak casually about weighty matters, nor solemnly about trivial ones; [...]. To express emotion, you will employ the language of anger in speaking of outrage; the language of disgust and discreet reluctance to utter a word when speaking of impiety or foulness; the language of exultation for a tale of glory, and that of humiliation for a tale of pity and so on in all other cases."

5 "[...] opportune or inopportune usage is a factor common to all species [of rhetoric]".

6 " This aptness of language is one thing that makes people believe in the truth of your story; their minds draw the false conclusion that you are to be trusted from the fact that others behave as you do when things are as you describe them ; and therefore they take your story to be true, whether it is so or not."

${ }^{7}$ Há na literatura outras explicações sobre a gênese de kairós. Esta, no entanto, parece-nos mais provável.
} vol.09, nº. 03, Rio de Janeiro, 2016. pp. 
intimamente relacionados: onde falta respeito ao kairós, não há decorum, e onde falta decorum, falta também o kairós. E ambos implicam respeito ao auditorium.

Em razão de Aristóteles não ter utilizado o termo kairós na Retórica, esse conceito parece ter sido negligenciado por muitos retóricos gregos e romanos. Certamente, no entanto, a ênfase na adequação contextual contida no kairós alinha-o com o to prepon aristotélico e, posteriormente, com o decorum romano.

Essa teoria sobre o kairós foi também aplicada pelo sofista Górgias de Leontinos em sua busca pela verdade e pela comunicação ética:

Aqueles [os que morreram na guerra] adquiriram, por um lado, a virtude divina, por outro lado, o caráter mortal do homem, [...] porque consagraram pelo uso a mais divina e mais universal lei: falar e calar, fazer e deixar de fazer o que se deve no momento que se deve._(GÓRGIAS, [ca. 490 a. C], apud BARBOSA \& CASTRO, 1993, p. 36, )

Vejamos agora como o conceito de decorum foi incorporado pelos diversos estudiosos através dos tempos e como é entendido na contemporaneidade.

\section{DECORUM NA ROMA CLÁSSICA}

A despeito das importantes contribuições sofísticas e aristotélicas que embasaram as reflexões posteriores sobre o decorum, de fato foram os romanos, principalmente, os que mais se dedicaram a pensar esse conceito e nele se pautaram.

\section{Cícero}

Devemos a Cícero, especialmente, as principais contribuições para o conceito de decorum. Ele o aborda em quatro de seus principais tratados: em De Oratore, em De Officiis, em Orator e em De Inuentione.

Em Orator, Cícero diz:

Essa, na verdade, é a forma da sabedoria que o orador deve empregar especialmente para adaptar-se às ocasiões e pessoas. $\mathrm{Na}$ minha opinião, não se deve falar com o mesmo estilo em todos os tempos, nem ante todas as pessoas, nem contra todos os adversários, nem em defesa de todos os clientes, nem em parceria com todos os defensores. Ele, [o sábio] será aquele que sabe adaptar seu discurso para caber em todas as circunstâncias concebíveis." (CÍCERO, Orator, 3.123, tradução nossa) ${ }^{8}$

\footnotetext{
8 "This, indeed, is the form of wisdom that the orator must especially employ--to adapt himself to occasions and persons. In my opinion, one must not speak in the same style at all times, nor before all people, nor against all opponents, not in defense of all clients, not in partnership with all advocates. He, therefore, will be who can adapt his speech to fit all conceivable circumstances."
} 
Por meio das palavras de Crassus, personagem de De Oratore, Cícero explica o que é ser indecoroso:

Pois quem não entende o que a ocasião demanda, ou fala demais, ou aparece demais ou não leva em consideração a posição ou os interesses daqueles em cuja companhia está, ou, em suma, que de um jeito ou de outro é do contra ou obstrutivo - tal pessoa é dita ser sem tato.(CÍCERO, De Oratore, 2.17, tradução nossa). ${ }^{9}$

Por outro lado, sobre o uso adequado de decorum, Crassus diz: "Aqueles que também regulam o seu discurso, do modo exigido pela relativa importância do assunto e das pessoas em causa, merecem elogios pela qualidade a que eu chamo de adequação e propriedade." (CÍCERO, De Oratore, 3.53, tradução nossa). ${ }^{10}$

Em Orator, Cícero diz ainda:

Mas o fundamento da eloquência, como de todas as outras coisas, é a sabedoria. Pois na vida, como em um discurso, nada é mais difícil do que ver o que é apropriado. Os gregos chamam a isto, to prepon., nós chamamos de decorum. Mas em referência a esse ponto, muitas regras admiráveis foram estabelecidas e vale a pena compreender o assunto. E é devido à ignorância a respeito que os homens mais incorrem em erros, não só na vida, mas muitas vezes nos poemas e nos discursos. No entanto o orador deve considerar o que é apropriado não só em suas sentenças, mas também em suas palavras. Pois não é toda a fortuna, nem toda a honra, nem todas as autoridades, nem todas as idades, ou lugar, ou tempo, nem todos os ouvintes devem ser tratados pelo mesmo tipo de expressão ou de sentimentos. E em todos os tempos, em toda parte de um discurso ou da vida devemos considerar o que é apropriado e que depende parcialmente dos fatos que são objetos da discussão e também do caráter daqueles que são os falantes e daqueles que são os ouvintes. . (CICERO, Orator, XXI, tradução nossa) ${ }^{11}$

Em De Officiis, Cícero focaliza mais a relação entre o decorum e os tipos de virtude moral, influência atribuída aos estoicos:

$\mathrm{Na}$ [propriedade] encontramos consideração e autocontrole, que dão, como se fosse uma espécie de esmalte para a vida; ela inclui também temperança, subjugação completa de todas as paixões e a moderação em todas as coisas [...].Pois empregar a razão e o discurso racionalmente, fazer com atenção

\footnotetext{
9 " For someone who does not understand what the occasion demands, or talks too much, or shows off, or takes no account of the standing or the interests of those whose company he is in, or, in short, who in some way or other is gauche or obtrusive - such a person is said to be tactless"

10 "Those who also regulate their speech in the way required by the relative importance of the subject matter and the people concerned, deserve praise for the quality that I call suitability and appropriateness"

11 "But the foundation of eloquence, as of all other things, is wisdom. For as in life, so in a speech, nothing is more difficult than to see what is becoming. The Greeks call this, we call it " to prepon." But concerning this point many admirable rules are laid down, and the matter is well worth being understood. And it is owing to ignorance respecting it that men make blunders not only in life, but very often in poems, and in speeches. But the orator must consider what is becoming not only in his sentences, but also in his words. For it is not every fortune, nor every honour, nor every authority, nor every age, or place, or time, nor every hearer who is to be dealt with by the same character of expressions or sentiments. And at all times, in every part of a speech or of life, we must consider what is becoming, and that depends partly on the facts which are the subject under discussion, and also on the characters of those who are the speakers and of those who are the hearers."
} vol.09, $\mathrm{n}^{\circ} .03$, Rio de Janeiro, 2016. pp. 
tudo que se deve fazer, e em tudo discernir a verdade e a fazer respeitar, isso

é decorum. (CICERO, De Officiis, 1.27.93-94, tradução nossa). ${ }^{12}$

Retóricas anteriores - e mesmo o próprio Cícero em outros textos - se voltam principalmente para um uso oratório, persuasivo, de decorum, mas em De Officiis, como se pôde ver, Cícero relaciona decorum à virtude ética da temperança, da modéstia, do pleno domínio das tribulações da alma, do senso de medida. Em suma, virtudes que têm em comum o limite e a adequação ao contexto.

Cumpre ressaltar que, em relação ao decorum, Cícero não só em teoria defende sua importância e validade. Também na prática, em seus próprios discursos ele respeita as exigências do decorum, apresentando-se como popular, quando se dirige a um público popular, embora, em escritos privados e nos discursos para audiências de elite, revele oposição a objetivos populares e preconceito contra as classes mais baixas. ${ }^{13}$

\section{Quintiliano}

Discípulo e seguidor de Cícero, Quintiliano, em Institutio Oratoria (95 d.C), aborda também o decorum e se refere a ele como "propriedade" ou " costume". A concepção de decorum de Quintiliano é decorrente de sua própria definição do orador ideal: vir bonus dicendi peritus [homem de bem, perito em falar] e, portanto, a ética é seu componente principal. Assim como Cícero em De Officiis, Quintiliano torna também mais complexa sua concepção de decorum, adicionando a ela uma concepção ética do que seja o "bem". Para ele, “costume" é viver de acordo com o "bem" (QUINTILIANO, Institutio Oratoria, 6.45).

Do ponto de vista linguístico, esse autor concentra-se principalmente em decorum como adequação na escolha de palavras, afirmando que as palavras não são por natureza boas ou más, mas podem ser apropriadas e aplicadas devidamente ou não. Ele destaca a necessidade de se aprender uma grande variedade de palavras para diferentes ocasiões, porque qualquer palavra pode ser excelentemente empregada num lugar ou outro; temos às vezes, até mesmo, ocasião para palavras baixas e grosseiras.

Para o autor, quando nosso discurso é bem adaptado ao nosso assunto, torna-se mais agradável. Sugere que o costume, em relação ao discurso, significa um acordo de eruditos quanto a como falar. (QUINTILIANO, Institutio Oratoria ,10.2.13).

\footnotetext{
12 "In [propriety] we find considerateness and self-control, which give, as it were, a sort of polish to life; it embraces also temperance, complete subjugation of all the passions, and moderation in all things...For to employ reason and speech rationally, to do with careful consideration whatever one does, and in everything to discern the truth and to uphold it- that is proper"

${ }^{13}$ Notamos aqui que Cícero, embora prezasse o decorum, como político e como retórico não tinha compromisso com a verdade.
} 
Quintiliano não se limita a enfatizar o aspecto estilístico do decorum. Para ele, deve-se guiar pelo decorum em todas as partes da Retórica, desde a inuentio até a pronunciatio, incluindo, portanto a persuasão. Para ele, há ocasiões em que o decorum impede o orador de persuadir, pois não se pode persuadir a qualquer custo, uma vez que seu ethos ficaria comprometido.

\section{A ABRANGênCIA do CONCEITO CLÁSSICO DE DECORUM}

A Encyclopedia of Rhetoric and Composition enfatiza a importância de decorum para o estudo da Retórica: "Decorum é o mais retórico dos conceitos de Retórica, uma ideia que permeia toda a Retórica clássica e um importante ponto de convergência dos conceitos social, moral e estético da tradição retórica." (tradução nossa) ${ }^{14}$

De fato o conceito de decorum apresenta interface com vários dos demais conceitos do arsenal retórico: (i) está presente nos gêneros judicial, legislativo e epidítico, estabelecendo o que é apropriado a cada um deles; (ii) participa da caracterização dos tipos de estilo e sua adequação aos tipos de discurso; (iii) relaciona-se às figuras retóricas quanto à sua adequação; (iv) desempenha papel importante na persuasão, parte essencial da Retórica: controlando o tipo de argumento a ser usado em uma dada situação discursiva; relaciona-se também às provas do ethos e do pathos, que são calibradas pelo decorum, estabelecendo seus limites; vincula-se também à stasis, procedimento retórico usado para descobrir o iudicatio da causa; e relaciona-se às falácias, argumentação contenciosa, censurando tal uso. Por fim, (v) estrutura a pedagogia retórica e seus procedimentos. Em suma, governa todo o uso da língua.

A despeito de tal abrangência, a relação do decorum com as provas retóricas do ethos e do pathos, dois dos três pilares da persuasão retórica, é, no nosso entender, a mais notável.

\section{Decorum e ethos}

Para Aristóteles, o orador, para persuadir sua audiência precisa apresentar um ethos positivo: mostrar-se sábio (phrónesis), bondoso, solidário (éunoia) e honesto e humilde (areté). O orador que apresenta um ethos negativo, revelando-se para a audiência individualista, narcisista, prepotente, incapaz de perceber o outro, ou de imaginar o outro é, portanto, incapaz de persuadir, pois age por constrangimento, por coerção, por anulação do

\footnotetext{
14 "Decorum is the most rhetorical of rhetorical concepts, an idea that permeates the whole of classical rhetoric, and an important point of convergence for the social, moral, and aesthetic concerns of the rhetorical tradition."
} vol.09, n. 03, Rio de Janeiro, 2016. pp. 
outro, por ultraje, em contraste com o preceituado como ethos positivo pela Retórica. É o decorum que exige do orador o ethos positivo.

\section{Decorum e pathos}

Aristóteles, quando trata da persuasão pelo pathos, que busca a adesão do auditório pelo apelo às emoções, apresenta, ao lado de diversas emoções, a v̈6pıs - hybris $-{ }^{15}$ (arrogância), como uma modalidade de ira, e a define como a atitude de ultrajar, vexar, humilhar a vítima e ter prazer com isso:

Da mesma forma, quem ultraja despreza. Consiste o ultraje em fazer e em dizer coisas que possam fazer sentir vergonha em quem as sofre, não porque haja outro interesse além do fato em si, mas por mero prazer. [...] aquilo que causa prazer a quem ultraja é o fato de eles pensarem que o exercício do mal os torna superiores.(ARISTÓTELES, Retórica. II, 1378b, tradução nossa) ${ }^{16}$

Hybris é, pois, uma emoção negativa, incompatível com areté, o termo grego que designa a qualidade daquele que detém um tipo de excelência que implica um esforço humilde e constante para alcançar a perfeição, com uma consciência realista de que tal perfeição não pode ser alcançada. O indivíduo que se esforça para fazer e ser o melhor alcança areté. Todavia, quando o indivíduo acredita que ele realmente já alcançou esse status, ele pode perdê-lo e cair em hybris, incapaz de reconhecer os limites pessoais.

Em seu livro Política, Aristóteles condena a hybris, atribuindo a ela até mesmo a causa de revoluções. (ARISTÓTELES, Política,V, 3)

Também Cícero, em De Inuentione, condena esse tipo de emoção: "Conquistaremos a boa vontade, a partir de [atitudes] de nossa própria pessoa, se nos referimos aos nossos próprios atos e serviços sem arrogância, [hybris] [...]” (CICERO, De Inuentione, 45, tradução nossa) ${ }^{17}$

Ainda em relação à hybris, assim aconselha Cícero em De Officiis: "Mas é uma coisa boa manter o mesmo semblante tranquilo, uma conduta imutável e um temperamento sereno em todas as condições de vida[...]" (CÍCERO, De Officiis, I,XXVI, 26,90, tradução nossa) ${ }^{18}$

\footnotetext{
${ }^{15}$ Embora Aristóteles arrole diversas emoções, mencionamos aqui somente a hybris (modalidade da ira), devido ao fato de essa emoção ser muito vinculada ao decorum, como veremos adiante. Outras emoções, como, por exemplo, a inveja, também são ligadas ao decorum.

16 "Insolence is also a form of slighting, since it consists in doing and saying things that cause schame to the victim, not in order that anything may happen to yourself, but simply for the pleasure involved. [...] the cause of the pleasure thus enjoyed by the insolent man is that he thinks himself greatly superior to others when ill-treating them."

17 "We shall win good will from our own person if we refer to our own acts and services without arrogance."

18 "But it is a fine thing to keep an unruffled temper, an unchanging mien, and the same cast of countenance in every condition of life"
} vol.09, nº 03, Rio de Janeiro, 2016. pp. 
Como se vê, em Aristóteles e Cícero é nítida a relação do decorum com o ethos e com o pathos.

Todavia, embora os retóricos clássicos enfatizem a importância do decorum, nenhum deles apresentou um conjunto de orientações que permitam a um estudante de oratória uma eficaz prática de decorum. Talvez porque não haja nenhuma resposta certa e unívoca para o que constitua um comportamento decoroso. Ou talvez porque a importância do contexto cultural e situacional seja tão sutil que seria um enorme compromisso estabelecer um único conjunto de regras prescritivas.

Encontram-se, no entanto, em alguns textos clássicos, alguns conselhos sobre como ser decoroso. Cícero, em De Officiis, recomenda o decorum, ilustrando-o com um caso de violação desse princípio:

Tal disciplina de conduta, portanto, deve ser observada, pois tudo na condução da nossa vida deve ser equilibrado e harmonizado, como em um discurso acabado. Por isso é indigno e altamente censurável, quando sobre um tema sério, apresentam-se brincadeiras que são apropriadas a um jantar, ou qualquer tipo de conversa imprópria. Quando Péricles se associou com o poeta Sófocles, como seu colega no comando, e tinham-se encontrado para conferenciar sobre assuntos oficiais que interessavam a ambos, um garoto bonito por acaso passou e Sófocles disse: "Olha, Péricles: que garoto bonito!" Quão pertinente foi a resposta de Péricles: "Silêncio, Sófocles, um general deve manter não só as mãos, mas seus olhos sob controle. E ainda, se Sófocles tivesse feito esta mesma observação em um julgamento de atletas, ele teria de suportar não apenas repreensão. Tão grande é a importância do lugar e circunstância.(CICERO, De Officiis, 144, tradução nossa) $)^{19}$

Na sequência, aconselha ainda Cícero:

Mas flagrantes violações de boa educação como cantar nas ruas, ou qualquer outra má conduta grosseira, são facilmente aparentes e não implicam especialmente admoestação e instrução. Mas é preciso ainda mais cuidadosamente evitar essas falhas aparentemente triviais que passam despercebidas por muitos. No entanto, mesmo que uma harpa ou flauta possam estar um pouco desafinadas, ainda assim a falta é detectada por um conhecedor; então devemos estar atentos para o fato de que talvez algo em nossa vida esteja desafinado - ou melhor, pelo contrário, muito maior é a necessidade cuidado, na medida em que a harmonia das ações é muito melhor e muito mais importante do que a harmonia de sons. .(CÍCERO, De Officiis, 145 , tradução nossa $)^{20}$

19 " Such orderliness of conduct is, therefore, to be observed, that everything in the conduct of our life shall balance and harmonize, as in a finished speech. For it is unbecoming and highly censurable, when upon a serious theme, to introduce such jests as are proper at a dinner, or any sort of loose talk. When Pericles was associated with the poet Sophocles as his colleague in command and they had met to confer about official business that concerned them both, a handsome boy chanced to pass and Sophocles said: "Look, Pericles; what a pretty boy!" How pertinent was Pericles's reply: "Hush, Sophocles, a general should keep not only his hands but his eyes under control." And yet, if Sophocles had made this same remark at a trial of athletes, he would have incurred no just reprimand. So great is the significance of both place and circumstance."

20 "But flagrant breaches of good breeding like singing in the streets or any other gross misconduct, are easily apparent and do not call especially for admonition and instruction. But we must even more carefully 
Como se pôde constatar, parece-nos que se reconhece melhor o que seja decorum pela sua ausência. A conduta decorosa é invisível pois é a normal, a default. O que chama a atenção do auditório são as atitudes indecorosas.

\section{DECORUM NO SÉCULO NO SÉCULO I: SANTO AGOSTINHO}

Depois de Quintiliano (95 d.C), foi de Agostinho de Hipona a primeira mutação do conceito clássico de decorum. Antes de se converter ao cristianismo, foi um retórico, seguidor de Cícero. Dada sua nova opção pela vida religiosa cristã, teve que adaptar sua Retórica, transformando-a de uma arte pagã em uma arte cristã. Em decorrência, em Agostinho, cujos objetivos eram tão somente os de um orador cristão, principalmente ensinar a fé e admoestar os fieis, houve um investimento na invenção de um novo tipo de decorum, uma adaptação do conceito à oratória cristã, diferente do conceito de Cícero, que era mais orientado pelos seus nobres propósitos retóricos. Para tanto, segue Agostinho estritamente a Bíblia Sagrada, defendendo e, até mesmo, imitando o estilo nela utilizado. (AGOSTINHO, De Doctrina Christiana, 426 d.C)

\section{DECORUM NA IDADE MÉDIA}

Na Idade Média, quando a Retórica se restringiu à arte de escrever cartas, ars dictaminis, o decorum foi o princípio norteador dessa arte.

Além disso, com a emergência do cristianismo, o conceito de decorum fundiu-se com os conceitos do sagrado e do profano. Embora nessa época temas religiosos tenham sido muitas vezes tratados com humor, num estilo "baixo", no drama medieval especialmente, as igrejas policiavam cuidadosamente o tratamento das formas de arte mais permanentes, insistindo em um estilo "elevado", para, assim, preservarem o decorum.

\section{DECORUM NO RENASCIMENTO}

No Renascimento, o conceito de decorum foi revificado, especialmente onde Cícero era considerado um modelo a ser imitado. No entanto, uma concepção de decorum religiosa, em continuidade à da Idade Média, também se fez presente, levando, por exemplo, a que a fusão

avoid those seemingly trivial faults which pass unnoticed by the many. However slightly out of tune a harp or flute may be, the fault is still detected by a connoisseur; so we must be on the watch lest haply something in our life be out of tune - nay, rather, far greater is the need for painstaking, inasmuch as harmony of actions is far better and far more important than harmony of sounds." 
de mitologia clássica e temas cristãos fosse considerada indecorosa. O Concílio de Trento, especificamente, proibiu, entre outras coisas, o indecoroso na arte religiosa.

Entretanto, quando o pensamento grego e romano foi resgatado na Renascença italiana e inglesa, o conceito de decorum foi reformulado e renomeado: cortesia. Trata-se também de uma mutação no conceito de decorum. Baltassare Castiglione, no século XVI, cujo trabalho se inspirou em De Oratore de Cícero, tenta preencher as lacunas dessa obra quanto ao decorum, escrevendo um manual prático sobre como agir com cortesia, Il Cortigiano (1528). Para Castiglione, decoroso é o cortesão que se destaca em atividades físicas, mantendo sempre a dignidade; que exibe moderação em tudo que faz; que é um conhecedor e praticante das artes e das letras; que evita a afetação e executa tudo com graça e aparentemente sem esforço. Para ele, a aparência externa é de extrema importância.

(CASTIGLIONE, B. [1528] 1959, p. 22-23).

Castiglione foi muito criticado por sua ênfase nas exterioridades e por sua pouca consideração pela ética.

\section{DECORUM NO SÉCULO XVII: SPINOZA}

No século XVII, Benedictus de Spinoza [1670], um dos grandes racionalistas do seu século, também se dedicou a pensar o decorum, principalmente em relação à vida pública.

Segundo ele, o decorum impõe limites aos que exercem funções públicas: quanto ao falar, quanto ao componente gestual do discurso e quanto ao escrever. No entender desse filósofo, para que os agentes públicos sejam temidos e respeitados, devem evitar toda fala e procedimentos que provoquem o riso ou a indignação das pessoas. Para ele, portanto, quem ocupa altos cargos não tem o direito de se exibir pelas ruas embriagado, sem roupas e na companhia de prostitutas. Além disso, deve se policiar em seus discursos. (SPINOZA, 2009, p.97)

\section{DECORUM NO SÉCULO XVIII: LORD CHESTERFIELD}

No século XVIII, no contexto britânico, decorum também começou a ser usado por Lord Chesterfield para designar os preceitos de etiqueta social, de boas maneiras, que prescreviam os limites dos comportamentos sociais dentro de uma dada situação. Para Chesterfield, decorum é "uma decência exterior geral, a adequação e propriedade de conduta, nas relações comuns da vida.” (CHESTERFIELD, L.,[1737] 2005, p. 189, tradução nossa) ${ }^{21 .}$

21 "[...] a general exterior decency, fitness and propriety of conduct in the common intercourse of life." 12011212 vol.09, n. 03, Rio de Janeiro, 2016. pp. 
Conforme Arditi (1998, p.274), Samuel Johnson, escritor e pensador inglês (17091784), maior crítico de Chesterfield, seu decorum mundano incute nas pessoas "a moral de uma prostituta com os modos de um mestre sala." ${ }^{22}$ Por outro lado, segundo o autor, alguns estudiosos da época o defendiam. Para Edmund Burke, filósofo, advogado e político angloirlandês (1729-1797), as boas maneiras defendidas por Chesterfield eram um reforço para a estabilidade da sociedade. Chegou mesmo a declarar que as boas maneiras são mais importantes que as leis. Da mesma forma, antes de Burke, John Locke (1632-1704) filósofo inglês e ideólogo do liberalismo, já havia estabelecido a conexão de boas maneiras com a estabilidade e a saúde de um regime democrático.

\section{DECORUM NO SÉCULO XIX: ROGER ASHAM}

No século XIX, Roger Ascham, gramático e retórico, preceptor da rainha Elizabeth I da Inglaterra, em seu livro The Scholemaster (1863) prescreveu alguns cuidados a serem tomados, visando a uma vida pública decorosa: "Se a duquesa vai ao baile da corte e se veste de modo mais rico do que a rainha, será indecorosa. Se ela for ao mesmo baile menos bem vestida do que as demais aristocratas será indecorosa." (ASCHAM, 1863, p. 132, tradução nossa) Para Asham, o decorum é um cálculo, dos mais difíceis, que permite a alguém encontrar o seu exato lugar no mundo político, social e religioso. É um exercício de respeito aos outros, e, sobretudo, um meio de garantir o respeito a si mesmo pelos demais. Assim, quem não tem prerrogativas, mas quer exercê-las, é indecoroso.

Ascham defende também o respeito ao leitor em todos os sentidos. Para ele, se um escritor não usa imagens no seu texto, é indecoroso, pois despreza a criatividade e o gosto do leitor. Se, pelo contrário, as usa em excesso, é indecoroso, pois despreza a inteligência e a cultura do leitor.

Em relação às autoridades públicas, diz que, se elas desejam ser respeitadas, devem respeitar o povo. Certas palavras, embora exatas, devem ser evitadas. Outras, por exemplo, os pronomes de tratamento, devem ser corretamente empregados.

\section{DECORUM NO SÉCULO XX}

A partir do século XX, como vimos, quando a Retórica clássica foi resgatada, graças, principalmente, a Perelman, as considerações sobre o decorum voltaram a ocupar alguns estudiosos.

22 "the morals of a strumpet with the manners of a dancing master." vol.09, nº. 03, Rio de Janeiro, 2016. pp. 
Embora Perelmann não tenha abordado explicitamente o decorum em suas obras, sem dúvida ele não deixou de considerar esse importante conceito, uma vez que alude ao conceito de kairós, quando diz que "A consideração essencial para o orador que se propõe a tarefa de persuadir indivíduos concretos é que sua construção da audiência deve ser adequada para a ocasião." 23 (PERELMAN, 1969, p.19, tradução nossa) Considerando a interface existente entre kairós e decorum, ou melhor, que o conceito de decorum tem sua gênese no conceito de kairós, pode-se dizer que este conceito, de algum modo, está presente em Perelman.

Kenneth Burke, contemporâneo de Perelman, disse, em 1950, que só se convence um homem na medida em que se fala a sua língua: gesto, tonalidade, ordem, imagem, atitude, idéia, identificando seus caminhos com o seu. Para esse retórico, algumas pessoas não se importam com o que os outros pensam ou sentem por elas. Segundo ele, cada um tem o direito de agir como quer, mas essa opção leva a repetidas falhas na persuasão. Em suma, para Burke, não se pode ser persuasivo e indecoroso ao mesmo tempo. Os dois conceitos são mutuamente exclusivos. (BURKE, 1968, p.184)

Como se vê, decorum, nas diversas épocas, teve tanto uma função retórica, como uma função ética, uma função religiosa e uma função social.

\section{DECORUM NAS INSTÂNCIAS JUDICIÁRIA E LEGISLATIVA}

Já no nascente direito romano, ajustando-se à austeridade da doutrina estóica, que considerava que a virtude era o maior bem e que o maior mal era não tê-la, era exigida uma postura decorosa dos pretores e dos jurisconsultos, que deviam se distinguir do povo pela grauitas e pelo decorum.

Encontram-se no Digesto de Justiniano (século IV d.C.), passagens interessantes que ilustram tais prescrições, como no exemplo abaixo:

Mas também ao conhecer as causas não se deve irritar contra aqueles que considera maus, nem é conveniente chorar a propósito das súplicas dos desgraçados. Isto, pois, não é próprio de um juiz constante e reto cujos sentimentos seu vulto descobre. E, em suma, o direito deve ser rendido de tal modo que ele aumente, com seu engenho, a autoridade de sua dignidade. (CORPUS JURIS CIUILIS, DIGESTO,. 1.18.19.1, p. 141)

Em outra oportunidade, aconselha-se ao juiz ser acessível às partes, mas evitar a familiaridade, "[...] visto que da intimidade comum nasce o desprezo pela dignidade." (CORPUS JURIS CIUILIS, DIGESTO, 1.18 .19 pr., p. 45 ). ${ }^{24}$

\footnotetext{
23 "The essencial consideration for the speaker who has set himself the task of persuading concrete individuals is that his construction of audience must be adequate to occasion."

24 “[...] nam ex conversatione aequali contemptio dignitatis nascitur" Tradução de Hélcio Maciel França Madeira.
} vol.09, n. 03, Rio de Janeiro, 2016. pp. 
Também Quintiliano traz algumas reflexões sobre o decorum no âmbito da justiça. Esse retórico considera que o ethos do orador é o elemento essencial da Retórica, e, portanto, é mais importante que a persuasão. Se se tiver que escolher entre salvar o ethos ou renunciar à persuasão (ao logos e ao pathos) deve-se optar por preservar o ethos. (QUINTILIANO, Institutio Oratoria ,11.1-2).

Essa posição de Quintiliano, se levada ao extremo, implicaria vários problemas, principalmente no âmbito da justiça: há certas coisas que um orador (um defensor) não pode fazer para salvar um réu. $\mathrm{O}$ orador (defensor) deve então recusar algumas causas, quando, sendo elas irremediavelmente indecorosas, não deixariam ileso seu ethos, sua dignidade? Haveria réus que não poderiam ser defendidos por nenhum orador (defensor)? Na verdade, Quintiliano apresenta uma saída, admitindo uma margem de manobra para o orador (defensor). Ele aconselha, nos casos em que haja algo desonesto, no caso ou na pessoa, a apresentá-los ao público como não tão imorais como de fato o são. ${ }^{25}$ Apesar de propor essa saída, continua insistindo no ponto de que o orador não pode persuadir seu auditório a qualquer custo.

No século XIII, o jurista alemão Christian Thomasius, filho do retórico Jakob Thomasius, também se debruçou sobre o decorum em meio a discussões teóricas sobre o Direito Natural Racionalista, quando trata da separação entre Direito e Moral. Para ele, o principal objetivo do ser humano é a busca da felicidade e a condição para obter a felicidade é a paz . Para tanto, preconiza três normas para a conduta humana: i) A norma da honestidade (o honestum), um dever interno, que é a mais perfeita, uma vez que tem a ver com o homem em si e que não deve ser seguida por causa de outros homens, mas por causa de si mesmo; ii) a norma da justiça (o iustum), uma obrigação externa, segundo a qual "ninguém tem o direito em si mesmo", visto que "todo direito é externo, não interno"; e o decorum, um bem externo intermediário, e por isso imperfeito. De fato, o decorum não tem existência independente; como já vimos, segundo os clássicos, pode manifestar-se em todo lugar, é amplo seu escopo de atuação. (THOMASIUS, 1998, p. 241)

Norberto Bobbio, comentando a posição de Thomasius, considera que ele, na realidade, não fez uma bipartição entre Direito e Moral, e sim, uma tripartição, uma vez que além de considerar o honestum e o iustum também inclui o decorum como uma das regras da conduta humana. (BOBBIO,N. apud GARCIA, M. L., 2006, p. 44)

Embora poucos juristas se refiram explicitamente ao decorum, considerando a relação do decorum com a ética, pode-se dizer que, de algum modo, esse conceito está presente nos

25 Como se vê, Quintiliano, assim como Cícero, preza muito o decorum, mas, como bom retórico, relativiza o valor da verdade. vol.09, n. 03, Rio de Janeiro, 2016. pp. 
construtos de muitos especialistas do direito. De fato, como se pode ver, foi exatamente no âmbito da justiça, principalmente nos tribunais de justiça, que o conceito de decorum sobreviveu em sua forma clássica, incluindo os aspectos retóricos, como os tipos de argumento que devem ser usados, bem como os aspectos éticos, além de aspectos relativos à etiqueta e ao ritual. .Evidência disso é o fato de os sistemas judiciários de inúmeros países adotarem códigos de ética para os juízes, nos quais os preceitos do decorum estão sempre presentes.

Considerando a íntima relação da justiça com o legislativo, também no parlamento o conceito de decorum sobreviveu. Nessa instância é comum, em vários países, a existência de códigos de ética que prescrevem suas regras e procedimentos.

Seja em relação ao judiciário ou ao legislativo, esses códigos apresentam preceitos sobre a linguagem, a terminologia, o comportamento, o ritual, a relação entre os membros, em suma, prescrevem, em suma, o decorum.

Também os códigos brasileiros - o Código de Ética e Decoro Parlamentar ${ }^{26}$ e o Código de Ética da Magistratura Nacional ${ }^{27}$ - incluem artigos que ilustram o vínculo desses códigos com o conceito de decorum.

\section{${ }^{26}$ CÓDIGO DE ÉTICA E DECORO PARLAMENTAR DA CÂMARA DOS DEPUTADOS}

Artigo que ilustra o vínculo deste código com o conceito de decorum:

\section{CAPÍTULO IV DOS ATOS ATENTATÓRIOS AO DECORO PARLAMENTAR}

$[\ldots]$

Art. $5^{\circ}$. Atentam, ainda, contra o decoro parlamentar as seguintes condutas, puníveis na forma deste Código:

I - perturbar a ordem das sessões da Câmara ou das reuniões de comissão;

II - praticar atos que infrinjam as regras de boa conduta nas dependências da Casa;

III - praticar ofensas físicas ou morais nas dependências da Câmara ou desacatar, por atos ou palavras, outro parlamentar, a Mesa ou comissão, ou os respectivos Presidentes;

IV - usar os poderes e prerrogativas do cargo para constranger ou aliciar servidor, colega ou qualquer pessoa sobre a qual exerça ascendência hierárquica, com o fim de obter qualquer espécie de favorecimento;

V - revelar conteúdo de debates ou deliberações que a Câmara ou comissão hajam resolvido devam ficar secretos;

VI - revelar informações e documentos oficiais de caráter reservado, de que tenha tido conhecimento na forma regimental; 14 Câmara dos Deputados

\section{${ }^{27}$ CÓDIGO DE ÉTICA DA MAGISTRATURA NACIONAL}

Artigos que ilustram o vínculo deste código com o conceito de decorum:

\section{DISPOSIÇÕES GERAIS}

Art. $1^{\circ} \mathrm{O}$ exercício da magistratura exige conduta compatível com os preceitos deste Código e do Estatuto da Magistratura, norteando-se pelos princípios da independência, da imparcialidade, do conhecimento e capacitação, da cortesia, da transparência, do segredo profissional, da prudência, da diligência, da integridade profissional e pessoal, da dignidade, da honra e do decoro.

\section{CAPÍTULO II}

\section{INDEPENDÊNCIA}

Art. $4^{\circ}$ Exige-se do magistrado que seja eticamente independente e que não interfira, de qualquer modo, na atuação jurisdicional de outro colega, exceto em respeito às normas legais.

\section{IMPARCIALIDADE}

Art. $8^{\circ} \mathrm{O}$ magistrado imparcial é aquele que busca nas provas a verdade dos fatos, com objetividade e 


\section{DECORUM E CULTURA}

Embora esses códigos brasileiros sejam semelhantes aos demais códigos de ética estrangeiros, uma vez que todos têm origem nos preceitos clássicos e incorporam as mutações sofridas pelo conceito clássico de decorum, as diversas culturas divergem muito quanto à adesão aos preceitos neles invocados. Vejamos, para exemplificar, as posturas quanto ao decorum nos Estados Unidos e no Brasil, analisando-as contrastivamente.

\section{Decorum nos Estados Unidos da América}

Nos Estados Unidos, observa-se muito rigor quanto ao decorum, não só no judiciário e no legislativo, mas também no executivo, embora não exista um código de ética específico para esse poder.

Para ilustrar a valorização do decorum pelos norte americanos, lembramo-nos de alguns casos de quebra de decorum que foram muito divulgados e censurados pela mídia americana. Três desses casos foram protagonizados por um Juiz da Suprema Corte, Samuel Alito. Uma vez ele quebrou o decorum da corte, franzindo os lábios, revirando os olhos para o teto e balançando a cabeça 'não', quando uma sua colega sênior, Juíza Ruth Bader Ginsburg, lia suas dissidências em dois casos que estavam sendo julgados.

fundamento, mantendo ao longo de todo o processo uma distância equivalente das partes, e evita todo o tipo de comportamento que possa refletir favoritismo, predisposição ou preconceito.

Art. 12. Cumpre ao magistrado, na sua relação com os meios de comunicação social, comportar-se de forma prudente e equitativa, e cuidar especialmente:

II - de abster-se de emitir opinião sobre processo pendente de julgamento, seu ou de outrem, ou juízo depreciativo sobre despachos, votos, sentenças ou acórdãos, de órgãos judiciais, ressalvada a crítica nos autos, doutrinária ou no exercício do magistério.

Art. 13.O magistrado deve evitar comportamentos que impliquem a busca injustificada e desmesurada por reconhecimento social, mormente a autopromoção em publicação de qualquer natureza.

Art. 16. O magistrado deve comportar-se na vida privada de modo a dignificar a função, cônscio de que o exercício da atividade jurisdicional impõe restrições e exigências pessoais distintas das acometidas aos cidadãos em geral.

Art. 22. O magistrado tem o dever de cortesia para com os colegas, os membros do Ministério Público, os advogados, os servidores, as partes, as testemunhas e todos quantos se relacionem com a administração da Justiça.

Parágrafo único. Impõe-se ao magistrado a utilização de linguagem escorreita, polida, respeitosa e compreensível.

Art. 25. Especialmente ao proferir decisões, incumbe ao magistrado atuar de forma cautelosa, atento às consequências que pode provocar.

Art. 26. O magistrado deve manter atitude aberta e paciente para receber argumentos ou críticas lançados de forma cortês e respeitosa, podendo confirmar ou retificar posições anteriormente assumidas nos processos em que atua. Art. 27.0 magistrado tem o dever de guardar absoluta reserva, na vida pública e privada, sobre dados ou fatos pessoais de que haja tomado conhecimento no exercício de sua atividade.

Art. 28.Aos juízes integrantes de órgãos colegiados impõe-se preservar o sigilo de votos que ainda não hajam sido proferidos e daqueles de cujo teor tomem conhecimento, eventualmente, antes do julgamento.

Art. 37. Ao magistrado é vedado procedimento incompatível com a dignidade, a honra e o decoro de suas 
Esse tratamento dispensado à Juíza Ginsburg, de 80 anos de idade, 17 anos mais velha e 13 anos mais antiga que Alito na Suprema Corte, foi considerado uma exposição de temperamento judicial inadequado, ou, mais precisamente, de destemperança judicial. Para os observadores, tal destemperança não agradou à audiência: várias pessoas suspiraram, mostrando o desagrado. E certamente não agradou também a eles.

Segundo Milbank, veterano observador da Suprema Corte, normalmente os Juízes afirmam suas divergências com palavras, não com gestos; Alito, entretanto, embora faça uso de seu direito à voz com prolixidade, frequentemente suplementa suas palavras com gestos "próprios de alunos do ensino médio". Ele acrescenta que não foi a primeira vez que esse Juiz violou o decorum. De acordo com Milbank, em outra oportunidade, Alito também olhou furiosamente para a Juíza Elena Kagan, revirou os olhos e balançou a cabeça, enquanto a Juíza Sonia Sotomayor estava falando. Antes já havia também balançado a cabeça, franzido a boca (dizendo não é verdade) quando o presidente Obama discursava na Suprema Corte. ${ }^{28}$

Como se vê, o decorum, devido principalmente pelos homens públicos de todos os poderes da federação, para os americanos é um valor de que não abrem mão: como se sabe, não admitem nem mesmo pequenos desvios comportamentais na vida privada dos políticos e tratam com mais rigor ainda seus Juízes da Suprema Corte, não admitindo nem mesmo pequenos desvios, quase imperceptíveis, nos gestos e olhares, considerados incabíveis no caso de juízes no exercício de suas funções. A mídia americana, por outro lado, muito contribui para a denúncia e divulgação dos episódios indecorosos, não só dos magistrados, mas também de todos que desempenhem, ou pretendam desempenhar, cargos e funções públicas. .

\section{Decorum na República Federativa do Brasil}

Embora, como vimos, nos Estados Unidos se registrem ocorrências de quebra de decorum, nota-se que essas são de pouca gravidade, se comparadas às ocorrências brasileiras. No Brasil, como se sabe, são muito comuns os episódios de quebra de decorum pelos homens públicos de todos os três poderes da União. No entanto, em franca oposição ao que ocorre nos EUA, no Brasil esses os episódios além de mais frequentes, são, no nosso entender, também mais graves. Pode-se dizer, também, que muito poucos são os brasileiros que parecem se incomodar com os comportamentos indecorosos dos homens públicos. Pelo contrário, quando o indecoroso ataca um representante do partido político de preferência dos cidadãos, estes passam a considerá-lo um herói nacional. Por outro lado, a mídia brasileira, mesmo quando 
eventualmente denuncia as violações ao decorum, (abusos aliás proibidos pelo Código de Ética da Magistratura Nacional e pelo Código de Ética e Decoro Parlamentar da Câmara dos Deputados), não lhes dá a devida ênfase nem o devido espaço. Nossos códigos de ética parecem "letra morta", fadados a permanecer só no papel.

\section{Decorum nos âmbitos do legislativo e do judiciário brasileiros}

No âmbito do legislativo, especialmente, os episódios de quebra de decorum costumam ultrapassar todos os limites: éticos, linguísticos, gestuais, da etiqueta, do ritual. Esses episódios são tão frequentes e tão expostos pela mídia que não é necessário ilustrá-los aqui. A situação é tão escabrosa que, como disse, sabiamente, John Locke, já citado acima, pode comprometer "a estabilidade e a saúde de um regime democrático". No entanto, não podemos generalizar, uma vez que nem todos os parlamentares são indecorosos: há muitos que sabem se portar.

Também na esfera do judiciário, até mesmo no Supremo Tribunal Federal (STF), cuja principal função é a guarda da constituição e cujos membros são cidadãos brasileiros de notório saber jurídico e reputação ilibada e que, portanto, deveriam ser um modelo de dignidade e ética para todos, deparamo-nos frequentemente com episódios de quebra de decorum. Embora aqui também não se possa generalizar, pois a grande maioria dos Ministros parece-nos decorosa, não se pode deixar de questionar inúmeras e nítidas ocorrências de violação do Código de Ética da Magistratura Nacional por Ministros do STF.

A respeito de comportamentos indecorosos de magistrados, diz Aristóteles: "Quando os magistrados são insolentes e arrogantes eles conspiram um contra o outro e também contra a constituição da qual deriva seus poderes,[...]" (ARISTÓTELES, Política,V, 3, tradução nossa)

Entendemos, portanto, com esse filósofo, que tais atitudes indecorosas reincidentes podem, no limite, acarretar desestabilização da constituição e, em decorrência, da democracia.

A título de ilustração, e para que se possam cotejar as violações havidas nos Estados Unidos e no Brasil, apresentamos alguns casos, no nosso entender de desrespeito a artigos do Código de Ética da Magistratura Nacional, em episódios protagonizados por Ministros e ex-Ministros do STF, todos eles denunciados pela mídia.

i) Art.4 ${ }^{\circ}$ Exige-se do magistrado que seja eticamente independente e que não interfira, de qualquer modo, na atuação jurisdicional de outro colega, exceto em respeito às normas legais.

Registram-se ocorrências de interferências descabidas e insultuosas na relação entre Ministros, em casos de dissidência entre eles. 
ii) Art. $8^{\circ} \mathrm{O}$ magistrado imparcial é aquele que busca nas provas a verdade dos fatos, com objetividade e fundamento, mantendo ao longo de todo o processo uma distância equivalente das partes, e evita todo o tipo de comportamento que possa refletir favoritismo, predisposição ou preconceito.

Registram-se casos que evidenciam nítido favoritismo ou preconceito político- partidário.

iii) Art. 12 (caput) Cumpre ao magistrado, na sua relação com os meios de comunicação social, comportar-se de forma prudente e equitativa, e cuidar especialmente:

$[\ldots]$

II - de abster-se de emitir opinião sobre processo pendente de julgamento, seu ou de outrem, ou juízo depreciativo sobre despachos, votos, sentenças ou acórdãos, de órgãos judiciais, ressalvada a crítica nos autos, doutrinária ou no exercício do magistério.

São inúmeros os casos de imprudência na relação de Ministros com a imprensa, e, em relação ao parágrafo II deste artigo, há casos em que Ministros emitem, na mídia, juízo depreciativo sobre decisões do STF, quando seus votos foram vencidos.

iv) Art. $13 \mathrm{O}$ magistrado deve evitar comportamentos que impliquem a busca injustificada e desmesurada por reconhecimento social, mormente a autopromoção em publicação de qualquer natureza.

Há índices de busca por reconhecimento social, em entrevistas concedidas por Ministros à mídia nacional e estrangeira, escrita e televisiva, em que seus pares e até mesmo nosso sistema jurídico foram desrespeitosamente criticados.

v) Art. $22 \mathrm{O}$ magistrado tem o dever de cortesia para com os colegas, os membros do Ministério Público, os advogados, os servidores, as partes, as testemunhas e todos quantos se relacionem com a administração da Justiça.

Parágrafo único. Impõe-se ao magistrado a utilização de linguagem escorreita, polida, respeitosa e compreensível.

Há casos de insultos por Ministros a seus pares, individualmente, ou mesmo englobando todos os demais membros do STF, desconstruindo o próprio órgão. Registram-se também casos de maus tratos a advogados das partes, a pessoal da mídia, a membros de outros órgãos do judiciário, à Ordem dos Advogados do Brasil (OAB). Quanto ao parágrafo único deste mesmo artigo, identificam-se casos de usos por Ministros, em plenário, de linguagem (vocabulário) incompatível com a importância do órgão, ao insultarem seus pares.

vi) Art. $26 \mathrm{O}$ magistrado deve manter atitude aberta e paciente para receber argumentos ou críticas lançados de forma cortês e respeitosa, podendo confirmar ou retificar posições anteriormente assumidas nos processos em que atua. 
São recorrentes os casos de atitudes de Ministros que revelam impaciência e não receptividade a argumentos e críticas de seus pares, mesmo quando expressos de forma cortês e respeitosa.

vii ) Art. 28 Aos juízes integrantes de órgãos colegiados impõe-se preservar o sigilo de votos que ainda não hajam sido proferidos e daqueles de cujo teor tomem conhecimento, eventualmente, antes do julgamento.

Em algumas oportunidades, é grande a previsibilidade dos votos a serem proferidos pelos Ministros, em razão de suas declarações à mídia.

Não é necessário aqui identificar os autores de tais violações, já que todas elas já foram denunciadas pela mídia e são facilmente localizáveis na Internet, inclusive no Youtube.

O nosso objetivo foi somente mostrar que a noção de decorum é sensível à cultura, o que se evidencia na diferença entre as atitudes a respeito nos Estados Unidos e no Brasil. Como se pôde ver, enquanto para os americanos pequenos gestos, para nós quase imperceptíveis, são levados a sério, faltas graves, no cenário brasileiro, são desconsideradas.

\section{DECORUM E ARROGÂNCIA}

Nas palavras de Maquiavel, "Dê o poder ao homem e descobrirá quem ele realmente é." Em adaptação popular, temos o dito: "Quer conhecer o vilão, dê-lhe o bastão". A citação de Maquiavel e sua adaptação popular nos levam a buscar entender a relação do poder com a arrogância, característica psicológica recorrente em muitos poderosos, vinculada à falta de decorum.

Pautando-nos em Aristóteles, com ele entendemos que grande parte desses episódios protagonizados por juízes brasileiros, investidos de grande poder, se devem à arrogância, à hybris, uma emoção negativa, indecorosa, vinculada à ira, como já mencionamos. Em seu livro Política, Aristóteles condena a hybris, arrogância, atribuindo a ela até mesmo a causa de revoluções. Em relação aos magistrados, retomando citação acima, diz que "Quando os magistrados são insolentes e arrogantes eles conspiram um contra o outro e também contra a constituição da qual deriva seus poderes, [...]” (ARISTÓTELES, Política, V,3, ${ }^{29}$ grifos nossos) Como se vê, Aristóteles, em sua sabedoria e conhecimento da psicologia do ser humano, parece pressagiar eventos do século XXI.

Em relação à hybris, também Cícero assim se manifesta em De Officiis, I, XXV, 89:

29 "When the magistrates are insolent and grasping they conspire against one another and also against the constitution from which they derive their power." vol.09, n. 03, Rio de Janeiro, 2016. pp. 
E ainda:

Também não devemos dar ouvidos àqueles que pensam que se deve exprimir uma raiva violenta contra os inimigos políticos e imaginar que tal é a atitude de um homem corajoso, grande de espírito. Pois nada é mais louvável, nada mais torna alguém um grande e proeminente homem do que a cortesia e paciência. De fato, em um povo livre, onde todos desfrutam de direitos iguais perante a lei, nós devemos nos disciplinar para a afabilidade e o que é chamado 'equilíbrio mental '[...] ${ }^{30}$ (CÍCERO, De Officiis, I, XXV, 89 , tradução nossa):

Mais uma vez, quando a sorte sorri e o fluxo da vida flui de acordo com nossos desejos, diligentemente evitemos toda arrogância, insolência e orgulho. Pois isso é um sinal de fraqueza, de ceder aos sentimentos, tanto no sucesso quanto na adversidade. ${ }^{31}$ (CÍCERO, De Officiis,1,XXVI,26,90, tradução nossa)

Segundo o historiador cultural Christopher Lasch (1991), assiste-se atualmente a uma valorização da arrogância que se revela de diversas formas e produz efeitos devastadores, pois ignoram-se os limites e mesmo a própria noção de limite. É um tipo de comportamento cuja ocorrência aumentou com o individualismo contemporâneo, com o que se chama o narcisismo das sociedades individualistas, com o neoliberalismo. A arrogância passa a ser considerada inevitável ou normal e está quase a tornar-se um valor, levando o indivíduo a se imbuir de sua pessoa a fim de "arrogar-se" uma posição dominante, de sair-se bem numa sociedade de concorrência e de competição. Tudo isso é potencializado com as facilidades de exposição da imagem do arrogante, com a espetacularização promovida pela mídia.

Em termos contemporâneos, entende-se pois, por arrogância, uma forma e expressão de exercício do poder, uma postura associada a algo negativo: é o engajamento em comportamentos que exageram o senso de superioridade de uma pessoa para depreciar os outros.(SILVERMAN et al., 2010, p. 37). Os indivíduos arrogantes projetam uma onipotência e invencibilidade, através de um discurso associado a um ego inflado pelo sentimento de detentor da verdade e de superioridade.

Com isso, segundo Silverman et al. (2010, p.39), os arrogantes muitas vezes impedem o efetivo funcionamento das instituições, pois ter um senso exagerado de superioridade restringe a busca de feedback e faz com que os arrogantes desconsiderem informações de diagnóstico no seu ambiente de trabalho: onde há arrogância, a interação é uma competição, ao invés de um esforço cooperativo. Ao tratar os outros como inferiores a si, o arrogante os

30 "Neither must we listen to those who think that one should indulge in violent anger against one's political enemies and imagine that such is the attitude of a great-spirited, brave man. For nothing is more commendable, nothing more becoming in a pre-eminently great man than courtesy and forbearance. Indeed, in a free people, where all enjoy equal rights before the law, we must school ourselves to affability and what is called 'Mental Poise".

31 "Again, when fortune smiles and the stream of life flows according to our wishes, let us diligently avoid all arrogance, haughtiness, and pride. For it is as much a sign of weakness to give way to one's feelings in vol.09, $\mathrm{n}^{\circ}$. 03, Rio de Janeiro, 2016. pp. 
incentiva a responder a seu ataque ou com um contra-ataque reativo também agressivo, desafiando sua autoridade, ou a reagir submissamente.

Em órgãos colegiados, que pressupõem decisões colegiadas, a presença da arrogância é especialmente devastadora, pois inibe a coesão de decisões, importante para o bom funcionamento de tal tipo de órgão.

O comportamento arrogante é um problema especialmente desafiador, pois os indivíduos arrogantes consideram seu próprio comportamento aceitável e, portanto, não monitoram suas ações ao interagir com os outros. (SILVERMAN et al., 2010, p. 57).

Segundo Leary, Bednarski, Hammon, \& Duncan (1997, p. 94), esse comportamento inclui desrespeitar os colegas e suas idéias, pretendendo ser mais sábio do que outros, não assumir qualquer culpa ou falha, atribuindo-as aos outros e, ainda, desprezando outras opiniões.

Arrogância é conceitualmente relacionada com características de personalidade como, por exemplo, o narcisismo. O narcisismo envolve fantasias de autoadmiração, autoestima excessiva e mania de grandeza, podendo manter-se restrito à esfera da intimidade, mas podendo, em interações sociais, levar à arrogância. A arrogância é, pois, a inflação do narcisismo do indivíduo que se manifesta em contextos interpessoais ao mesmo tempo para depreciar os outros e para se valorizar, e objetiva, principalmente, fazer os outros sentirem-se inferiores.

No nosso entender, faltou aos estudiosos contemporâneos da arrogância, vinculá-la, como Aristóteles o fez, ao conceito de decorum. Sem dúvida, atitudes arrogantes são indecorosas, e, como todas atitudes desse tipo, precisam ser combatidas pela moral, pela ética, pela valorização do respeito e da dignidade devidos à qualquer indivíduo; é necessário opor-se a essas formas insidiosas de dominação, e, até mesmo, recusar uma oposição demasiado nítida entre o poder dominante (muitas vezes arrogante) e o despoder dos dominados (muitas vezes obrigados a sofrer passivamente as manifestações de arrogância).

\section{CONSIDERAÇÕES FINAIS}

O objetivo deste nosso trabalho foi, principalmente, mostrar como a sabedoria dos clássicos, que influenciou milênios, ainda tem lugar na contemporaneidade. Refletindo sobre o conceito de decorum e mostrando como ele foi pensado e respeitado através dos tempos, tivemos a pretensão de revitalizá-lo para que ele passe a ser, na nossa cultura, a exemplo de 
outras, um valor do qual não possamos abrir mão. A permanência do conceito de decorum através dos milênios é um índice irrefutável de sua importância e da necessidade de seu cultivo.

Considerando a importância inegável do legislativo e principalmente do judiciário nos estados democráticos de direito, defendemos que todos os órgãos dessas instâncias devem se pautar nas normas prescritas pelos códigos de ética e decorum institucionalizados, independentemente das posturas teórico-jurídicas, das convicções ideológicas e das tendências político-partidárias de seus membros.

Embora nossas reflexões tenham se restringido ao poder legislativo e ao poder judiciário, cumpre acrescentar que também os integrantes do poder executivo e do "poder" militar devem zelar pelo decorum em respeito ao cidadão e em respeito à Constituição. Não se pode esquecer de que, nas democracias, é o povo que detém a maiestas. A cada eleição, ele a cede temporariamente aos que elege para representá-lo. É por esta razão que o decorum exige que os cidadãos sejam tratados com respeito pelas autoridades. O povo soberano é quem lhes confere a autoridade.

Por fim, cumpre ressaltar que o decorum não deve ser uma exigência só para os homens públicos, mas deve ser exigido de todos os cidadãos. A condição para a cidadania plena inclui direitos e deveres: se o cidadão, por um lado, tem o direito de ser tratado com decorum, por outro lado ele próprio deve respeitar o decorum.

\title{
ON DECORUM: FROM THE CLASSICS TO POSTMODERNITY
}

\begin{abstract}
Considering that the observance of decorum is important to assure good human relationships, especially in the public sphere, and, also, that episodes of breach of decorum are recurrent in Brazilian public life, I propose to recover this classical concept, since its re-evaluation is opportune and urgent. I present therefore a historical revision of the concept of decorum starting from the classics and find that, although this concept has undergone changes, its fundamental aspect, the intimate connection with ethics, has been maintained until the present day. Evidence that this classical concept still survives is the existence, in many countries, of "codes of ethics and decorum" of legislative, judicial and other organs. I find, however, that this concept is sensitive to culture, which is proven in the contrastive analysis of a sample of episodes of the violation of decorum by judges of the American Supreme Court and of the Brazilian Supreme Court. I found that, although violations of Americans are less severe than Brazilians, the reactions of the media and American citizens are much more energetic, because decorum for the Americans is a value that they hold dear, while in Brazil it is a dead letter, lacking be ressurected. I also present some reflections on the arrogance of those who hold power, an attitude to which I attribute the cause of many occurrences of the breach of decorum nowadays.
\end{abstract} vol.09, n. 03, Rio de Janeiro, 2016. pp. 
Keywords: decorum; historical revision; contrastive analysis; Brazil; United States of America

\section{REFERÊNCIAS}

AGOSTINHO, S.. De doctrina Christiana. Oxford Early Christian texts. R.P.H. Green (ed. and trans.). Oxford: Clarendon Press, 1995.

ARDITI, Jorge. A Genealogy of Manners: Transformations of Social Relations in France and England from the Fourteenth to the Eighteenth Century. Chicago: Chicago University Press, 1998.

ARISTOTLE. Art of rhetoric. Trad. de J.H. Freese. Cambridge, London: Harvard University Press. 2000.

Aristotle's Politics. 2. ed. Carnes Lord, org., Trad. Benjamin Jowett, Chicago and London: The Chicago University press, 2013

BARBOSA \& CASTRO. Górgias: Testemunhos e Fragmentos. Lisboa: Colibri, 1993.

BEDNARSKI, R. Leary, M. R., Hammon, D., \& Duncan, T. Blowhards, snobs, and narcisists: Interpersonal reactions to excessive egoism. In R. M. Kowalski (Ed.), Behaving Badly: Aversive Behaviors in Interpersonal Relationships (pp. 111-131). New York, NY: Plenum, 1997.

BRASIL. Código de Ética da Magistratura Nacional. Conselho Nacional de Justiça. 06 de agosto de 2008 (Legislação brasileira).

BRASIL. Código de Ética e Decoro Parlamentar da Câmara dos Deputados. Brasil. Congresso Nacional. 2. ed. - Brasília : Câmara dos Deputados, Edições Câmara, 2010. 44 p. (Série textos básicos ; n. 54)

BURKE, Kenneth. A Rhetoric of Motives. Berkerley: University of California Press, 1969.

CASTIGLIONE, Baltassare. Libro del cortegiano, . Busi. A e Covito, C.Milano: Ed. Rizzoli, 1993.

CHESTERFIELD, L. Chesterfield Letters. Oxford Worlds Classics, Ed. David Roberts. Oxford: Oxford University Press, 2005

CICERO, Marcus T. On Duties, trans. M. T. Griffin and E.M. Atkins, New York: Cambridge University Press. (Citado como De Officiis.), 1991.

CICERO, Marcus T. De Inuentione. trad. Bulmario Reyes Coria. Cidade do México: Ed. vol.09, n. 03, Rio de Janeiro, 2016. pp. 
Universidade Autónoma de México, 2010.

CICERO, Marcus T. On the Ideal Orator, trad. James M. May and Jakob Wisse. New York: Oxford University Press. Cited parenthetically as De Oratore, 2001

CICERO, Marcus T. Brutus, Orator, trad.. G. L. Hendrickson and H.M. Hubbell. Cambridge, MA: Harvard University Press, 1939.

DIGESTO DE JUSTINIANO: Introdução ao Direito Romano. $4^{\mathrm{a}}$ Ed. trad. De Hélcio Maciel França Madeira. Revista dos Tribunais, São Paulo: Thomson Reuter, 2009.

ENOS, Theresa. (org.) Encyclopedia of Rhetoric and Composition. Communication from Ancient Times to the Information Age. New York: Routledge, 1996.

GARCIA, M.L. A histórica distinção entre ética pública e ética privada e sua incidência na construção do conceito de direitos fundamentais. Revista Brasileira de Direito Constitucional - RBDC n. 8 - jul./dez. 2006.

LASCH, Christopher. The Culture of Narcisism: American Life in an Age of Diminishing Expectations. New York: Norton, 1991.

PERELMAN, Chaïm. The New Rhetoric. Trans. John Wilkinson and Purcell Weaver. Notre Dame: The University of Notre Dame Press, 1969.

QUINTILIAN. Institutio Oratoria of Quintilian. Trad. H.E. Butler. 4 vols. The Loeb Classical Library. Cambridge: Harvard University Press, 1920.

SILVERMAN, Stanley B. et alii. Arrogance: A Formula for Leadership Failure. The Industrial-Organizational Psychologist, n.2, July 2012

SPINOZA, Benedictus de. Ética. Tradução de Tomaz Tadeu. Belo Horizonte: Autêntica Editora, 2009.

THOMASIUS, Christian. Historia algo más extensa del Derecho Natural. Tradução esp. de Salvador Rus Rufino e M. Asunción Sanches Manzano. Madrid: Tecnos, 1998. (Paulo plenior historia iuris naturalis, 1719).

Trabalho enviado em 06 de janeiro de 2016.

Aceito em 23 de março de 2016. 